\title{
Characteristics of Dissimilar FSW Welds of Aluminum Alloys 2017A and 7075 on the Basis of Multiple Layer Research
}

\author{
Krzysztof Mroczka, Anna Wójcicka, and Adam Pietras
}

(Submitted December 29, 2012; in revised form April 18, 2013; published online May 8, 2013)

\begin{abstract}
This work is concerned with the structure of the FSW joint of 2017A/7075 aluminum alloys, which was analyzed on the basis of a number of longitudinal and cross-sectional sections. Various ways and degrees of alloy stirring were identified, depending on the distance from the face of the weld. Furthermore, considerable variation in the length of the weld microstructures was demonstrated, reflecting the variability of the welding process. Studies of mechanical properties are also presented-the distributions of hardness on individual layers. A significant effect of plastic deformation on the hardness of the alloy 7075, which strengthened in deformed areas and shows weakness in the heat-affected zone, was noticed. The influence of the weld structure on the fracture of the sample, which was broken in the static tensile test, was analyzed applying scanning electron microscopy. The presence of non-deformed areas was revealed within the ductile fracture of the sample.
\end{abstract}

Keywords advanced characterization, aluminum, joining, metallography, optical microscopy, welding

\section{Introduction}

Friction stir welding technology is used for welding aluminum alloys (which are unweldable using conventional fusion welding methods) (Ref 1) and materials differing in terms of chemical composition and microstructure, such as Al-Cu and Al-steel (Ref 2). The main advantages of FSW are that the process is conducted in the solid state (Ref 3 ) and that the material is exposed to a much smaller amount of heat (a lower process temperature) than in conventional welding (Ref 4). Al-Mg-Zn alloys (7xxx series) tend to lose strength in the heat-affected zone (HAZ) due to changes in the structure of precipitates. These materials are precipitation strengthened (hardened), mainly though GP zones and metastable and stable $\mathrm{MgZn}_{2}$ phases, though it should be added that the transition phase to the stable phase takes place below $300{ }^{\circ} \mathrm{C}(\operatorname{Ref} 5,6)$. However, as a result, these materials can be easily subjected to supersaturation during welding, especially in the middle points of FSW joints (where the material is deformed plastically and the temperature is higher), and then strengthening as a result of aging (Ref 5-8). This process occurs much less easily in precipitation-strengthened alloys hardened by phases with $\mathrm{Cu}$ (2xxx series alloys), and hardness is usually reduced only at the weld area of the joints of these alloys (Ref 7). It must be

Krzysztof Mroczka, Anna Wójcicka, Institute of Technology, Pedagogical University of Cracow, ul. Podchorazych 2, 30-084 Krakow, Poland; and Adam Pietras, Institute of Welding, ul. B1. Czeslawa 16-18, 44-100 Gliwice, Poland. Contact e-mail: kmrocz@gmail.com.

remembered, however, that the strengthening of the material depends not only on the condition and amount of hardening precipitates but also on the grain size (Ref 9) and the density of dislocations (Ref 6). Both factors in FSW joints play an important role because dynamic recrystallization occurs to create the microstructure built of small, equiaxial grains [in the center of the weld (Ref 1)] and there is an increased density observed in dislocations (Ref 10). Both the macro- and microstructures of the FSW joints are highly heterogeneous and diversified. Finally, the structure of FSW joints depends on many factors, including welding parameters (Ref 1), the FSW tool (Ref 11), the welded materials, external conditions (Ref 5), the position of the alloys in terms of movement of the tool (for dissimilar joints), the location of the axis of the tool relative to the edge welding materials, etc. An analysis of the microstructure of dissimilar joints provides additional information because it is easier to identify specific areas of joints made of markedly different alloys. Moreover, studies on FSW welds made with aluminum alloys $2 \mathrm{xxx}$ and $7 \mathrm{xxx}$ series using the parameter space and the tools implemented here are scarce, as is the structural characterization of multiple longitudinal sections. Therefore, we present below the structure of FSW joints of aluminum alloys 2017A/7075 developed on the basis of the analysis of numerous cross sections.

\section{Experimental Method}

The materials used in this study were aluminum alloys 2017A-T6 and 7075-T6 in the form of sheets of thickness of $6 \mathrm{~mm}$. The chemical composition of alloy 2017A was as follows: $3.9 \% \mathrm{Cu}, 0.6 \% \mathrm{Mn}, 0.6 \% \mathrm{Mg}, 0.4 \% \mathrm{Si}$, and balance $\mathrm{Al}$; whereas that of alloy 7075 was as follows: $1.63 \% \mathrm{Cu}$, $5.72 \% \mathrm{Zn}, 2.49 \% \mathrm{Mg}$, and balance $\mathrm{Al}$, both in wt $\%$. Butt joints were made parallel to the rolling direction at the rotation speed 
of $450 \mathrm{rpm}$ and a linear velocity of the tool of $4.7 \mathrm{~mm} / \mathrm{s}$. The welding process was performed using a conventional tool: a threaded pin with a diameter of $8 \mathrm{~mm}, 4.6 \mathrm{~mm}$ length, and a shoulder with a diameter of $25 \mathrm{~mm}$; the angle between the tool shoulder and the surface of the welded sheets was $1.5^{\circ}$. The welding line was shifted $2 \mathrm{~mm}(1 / 4$ pin tool diameter) toward alloy 2017A. As a result, alloy 7075 was less stirred. The investigated sample (the joint) was artificially aged at $150{ }^{\circ} \mathrm{C}$ for $8 \mathrm{~h}$ (post-welding heat treatment).

The microstructure investigations were conducted using an OLYMPUS GX51 optical microscope with Nomarski differential interference contrast and a Philips 525M scanning electron microscope (SEM). The optical microscopic observations were performed on the cross section and longitudinal sections-layers (parallel to the face of the weld) that were ground and polished mechanically, and then etched with $2 \mathrm{~mL} \mathrm{HF}, 4 \mathrm{~mL}$ $\mathrm{HNO}_{3}$, and $94 \mathrm{~mL} \mathrm{H} \mathrm{O}$ solution. Macrostructures were obtained as a composite of 32 images taken from the light microscope, which have been put together in ICE software, Microsoft. The ICE software application to create macrostructures is described by Wojcicka et al. (Ref 12).

The SEM studies were conducted on fractures formed during rupture in a static tensile test. The tested samples were cut perpendicular to the line of welding. The studies of the mechanical properties were carried out to determine the hardness profiles $\mu \mathrm{HV} 0.2$ at sections-layers (mentioned above) located at a distance of $0.8,1.6,2.4,3.2,4.0,4.9$, and $5.5 \mathrm{~mm}$ from the surface (face of the weld) in the direction also perpendicular to the welding line.

\section{Results and Discussion}

\subsection{Macro/Microstructure}

For a better understanding of the FSW joint structure and how the material flows when the weld is created, the microstructure analysis and microhardness measurements were performed. The investigations were conducted on many longitudinal sections, located at different distances from the face of the weld, and the cross section. A cross section of the tested weld is shown in Fig. 1. Aluminum alloy 7075 is placed on the advancing side (left-hand side of Fig. 1). In this figure, the distances from the face of the joint $(0.8,2.4,3.2,4.0,4.9 \mathrm{~mm})$ of the surfaces (layers L1-L5) are marked. These layers were microscopically observed and microhardness measurements were carried out. Analysis of the macrostructure shows elements typical of conventional FSW joints: lack of symmetry, a clearly delineated boundary (a plane) of the area on the advancing side transformed by the recrystallization process and a softly changing microstructure of the retreating side, a visible weld nugget composed mainly of the alloy located on the advancing side, and the middle part of the weld transformed by recrystallization. The advancing side of the weld consists of the recrystallized alloy 7075 (area 1 in Fig. 1), but the center and the retreating side are composed of 2017A alloy (also after recrystallization). There are separated areas of alloy 2017A within the 7075 alloy (area 2 in Fig. 1-bright field) in the weld nugget. A small discontinuity of the microstructure is also observed (area 3, Fig. 1). The weld nugget does not contain any signs of the multilayer structure described in the literature as the "onion rings/structure," which is observed in many types of joints of aluminum alloys (series 2xxx, 5xxx, 6xxx) and magnesium (Ref 13, 14). According to da Silva et al. (Ref 15), the "onion" microstructure may occur in the joints of aluminum alloys of this type (2024/7075), but rather it is observed in the joints welded with a higher rate of tool rotation (1000 and 1400 $\mathrm{rpm})$. Then, the temperature of the process grows as does the intensity of the materials' mixing.

The macrostructure of layers (L1-L5) of the weld is shown in Fig. 2, 3, 4, and 6, which are marked at the cross section-Fig. 1. The first analyzed layer (L1-the distance from the face of the weld is $0.8 \mathrm{~mm}$ ) is shown in Fig. 2. One could expect substantial mixing of the material in this area-near the face, the material is mixed by the pin, but in the first place by the tool shoulder (Ref 16). Meanwhile, the microstructure contains a number of discrete areas with sharply marked boundaries. When viewed from the left-hand side (the advancing side), the weld consists of the parent material (alloy 7075), the HAZ and the thermo-mechanically affected zone (area no. 1, Fig. 2), and the area of the pin workplace, the border of which is marked with a dashed line (Fig. 2). The designation of this boundary was based on a detailed analysis of the microstructure (such as the bands of precipitates). The considerable accuracy (resolution) image of the microstructure results from the fact that the analyzed macrostructure is a composite of 32 images taken with a light microscope. In turn, the area of the pin workplace consists of the areas containing alloy 7075 (but with unequal participation of alloy 2017A (lighter band) - area no. 3) and alloy 2017A - area no. 2, Fig. 2. The dotted line in this figure indicates the approximate location of the contact plates $(7075 / 2017 \mathrm{~A})$ before welding-keep in mind that welding was performed with a shift welding line (an axis of symmetry of the tool) in the direction of the alloy 2017A. The analysis showed a fine-grained (subject to recrystallization) microstructure, the presence of defects (discontinuities of microstructure-area 4-probably due to

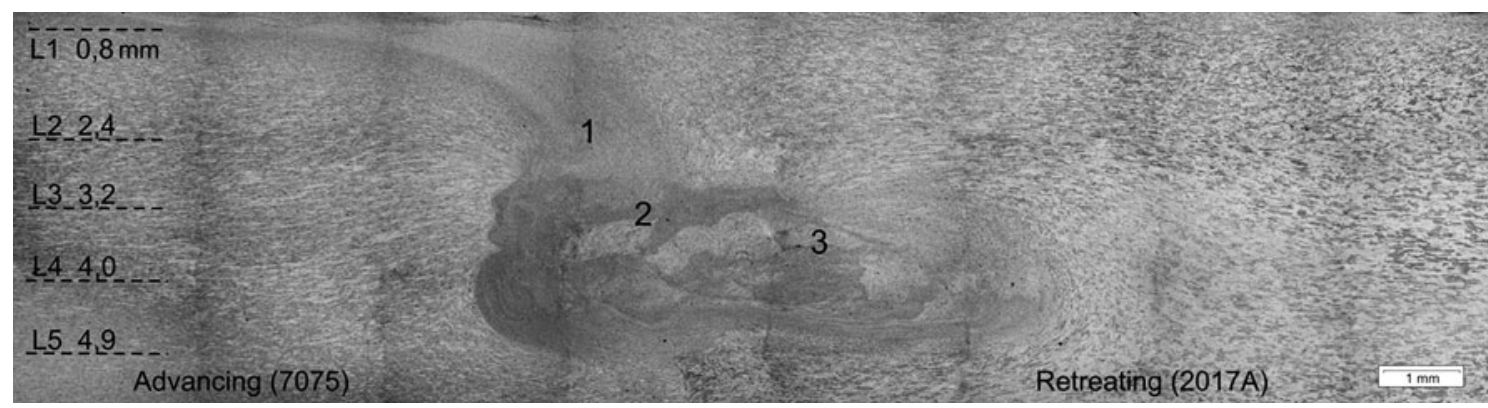

Fig. 1 Macrostructure of a cross section of the weld; the face of the weld is on the top 
insufficient plasticity of the material), and cracks (indicated with an arrow), which are probably related to the brittleness of alloy 7075; as reported by Rajakumar et al. (Ref 8), alloy 7075 FSW joints may contain various types of defects. It can be concluded that near the face of the weld, the material is structurally heterogeneous and different areas of the microstructure have sharp boundaries (in the form of planes). It is difficult to indicate a clear reason for the microstructure of the material. However, the changing conditions during the welding process, which are likely the result of imperfections in the

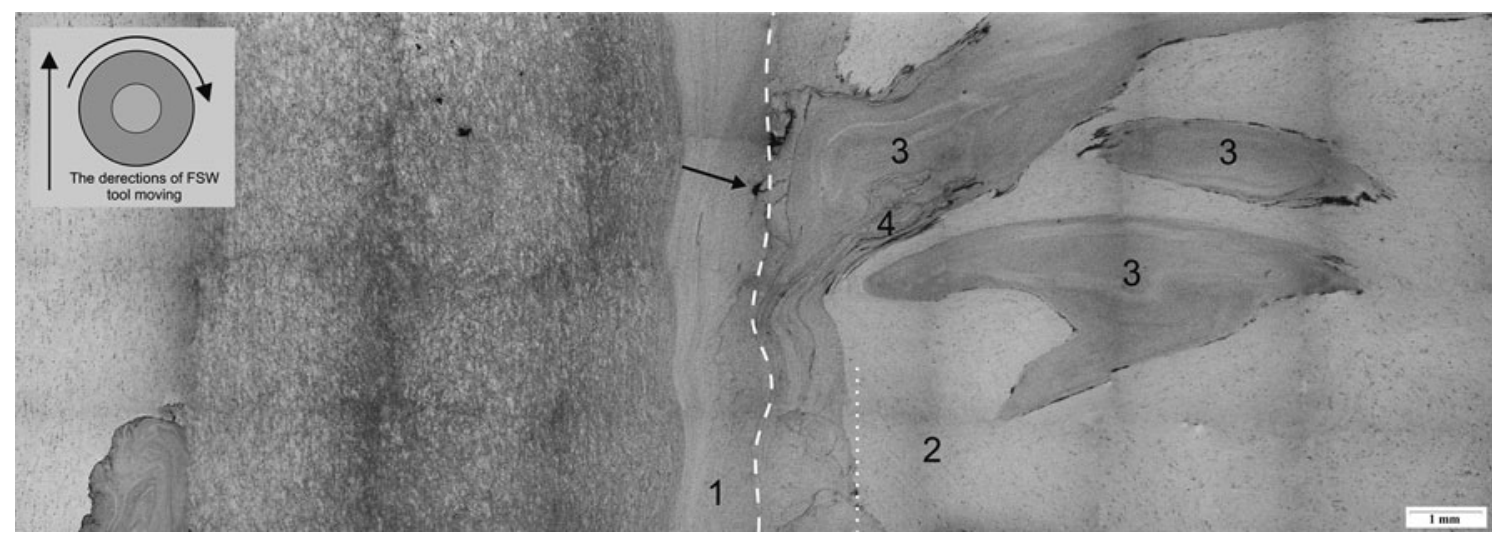

Fig. 2 Macrostructure of L1 layer of the weld $-0.8 \mathrm{~mm}$ from the face of the weld

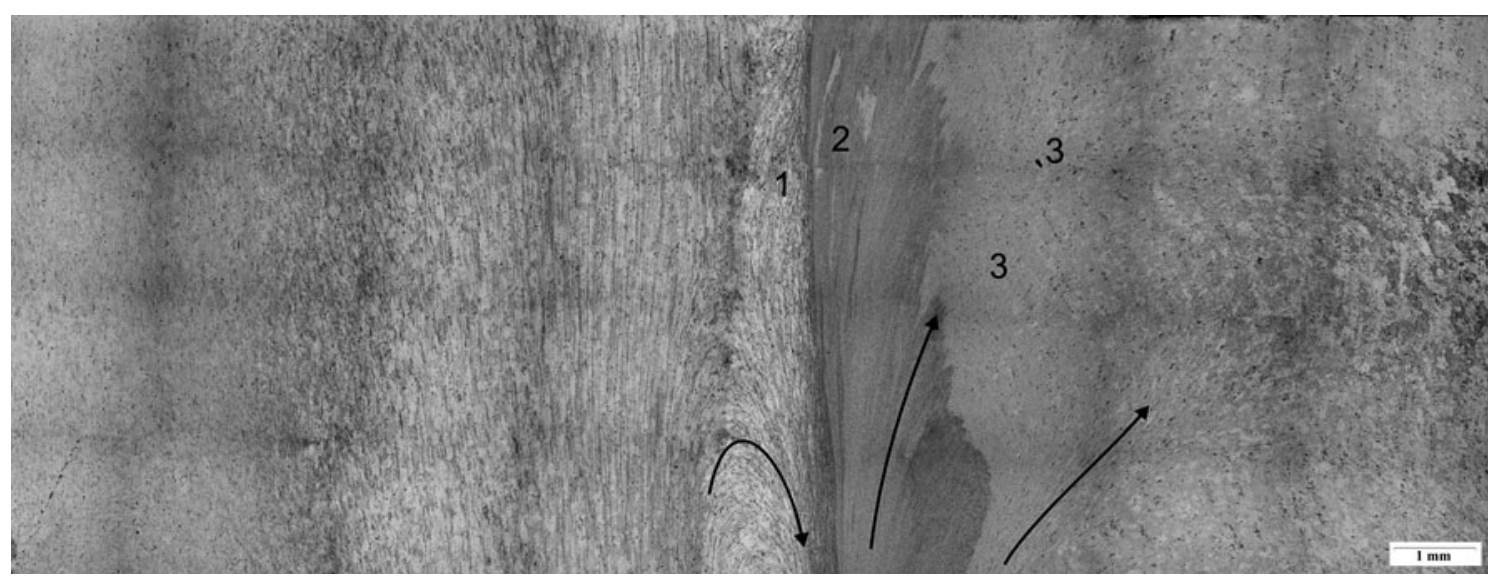

Fig. 3 Macrostructure of the L2 layer of the weld $-2.4 \mathrm{~mm}$ from the face of the weld

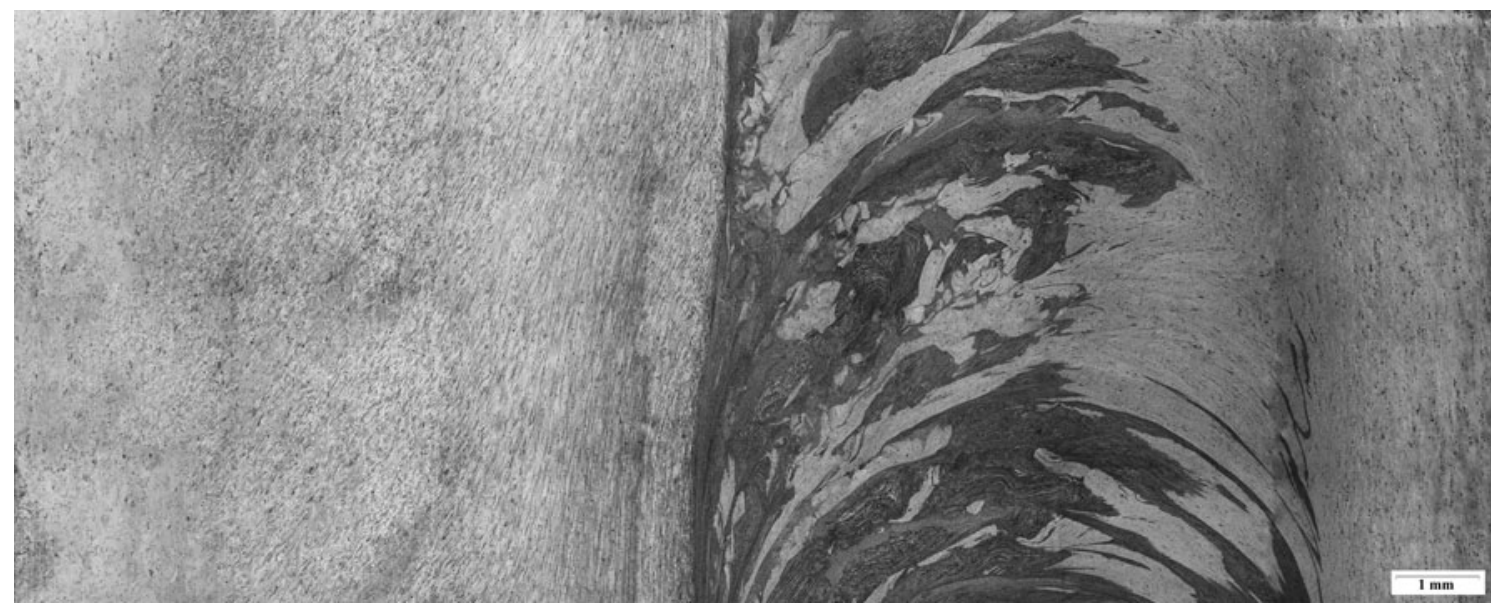

Fig. 4 Macrostructure of L4 layer of the weld $-4.0 \mathrm{~mm}$ from the face of the weld 
shape of plates (their flatness, uneven edges), could be taken into account. These types of microstructure elements were not identified in the joints of dissimilar aluminum alloys described in the literature (Ref $15,17,18)$. Because of the small size of layers and their location close to the edge of the sample (near the face and also the bottom of a weld), examining them on a cross section is very difficult.

The layers of material located at a greater distance from the face of the weld are deformed mainly by the pin, though of course the participation of the tool shoulder in the formation of the microstructure of the material in these areas is significant too. In Fig. 3, the layer L2 microstructure is shown. The L2 layer location on the cross section of the weld is presented in Fig. 1. One can see the direction of material flow resulting from the movement of the tool presented before - in the corner of Fig. 2. The directions of the material flow were marked on the basis of the precipitates' pattern, as indicated by the arrows in Fig. 3 referred to before. It should be borne in mind, though, that these are just the resultant directions observed and marked on the XY plane of the analyzed layer, and they are components of the actual flow directions in 3D. However, despite the fact that only a $2 \mathrm{D}$ analysis was performed, a number of important observations can be made. On the border area of the pin's workplace (the advancing side), the material deforms in a direction opposite to the direction of the flow of the material resulting from the direction of the tool's rotation-Fig. 3, the bottom of this figure. The directions of the flow for both alloys are clearly indicated (alloy 2017A on the right) in the area of the pin's workplace. Following the FSW tool (toward the top of the figure), we can see a different layout of precipitates suggesting convergence of the flow lines - area 1, Fig. 3. In the vicinity of this area, we can see the bright area of alloy 2017A in alloy 7075 (area 2), which indicates transport of large quantities of the material from the retreating side. In addition, some areas (marked No. 3) were observed where one cannot clearly indicate the directions of flow of the material (alloy 2017A). These observations confirm once again the variability of welding conditions and thus the directions of the material flow during FSW. An analysis of weld cross sections described in the literature, e.g., (Ref 19), shows the presence of a sharp boundary between the individual areas of the advancing side of the weld. The probable reason for this is precisely that portions of the material were flowing in the opposite directions (Fig. 3), which provides a very good connection - a typical friction one. The opposite material flow in the TMAZ may be the result of a slightly higher temperature and lower stress behind the FSW tool. Hamilton (Ref 20), among others, shows the model of temperature distribution in the FSW weld.

Much more interesting observations are made in the layer located approximately $4 \mathrm{~mm}$ from the face of the weld, which crosses the so-called weld nugget-Fig. 4. One can clearly define the scope of the direct impact of the pin tool. An analysis of the microstructure also shows why some authors report that the weld nugget is made of material that is on the advancing side and others claim that it is composed of material derived from the retreating side. The way in which the material is mixed in this area is highly diversified and probably strongly linked to the quality of the surface and edges of the welded sheets and also to their mechanical properties. In the case of the tested joint, we can identify the presence of alloy 7075 (mostly) (from the advancing side) in the weld nugget. At the FSW joint's cross sections - both similar and dissimilar ones - the weld nugget area is often structurally cohesive [no distinct boundary (Ref 19)] with a bend of recrystallized material extending from the advancing side to the weld nugget. This bend is called the "flow arm." The flow arm can be connected to the weld nugget without clear boundaries between these areas (Ref 19), or with a separate weld nugget area (Ref 14), especially at joints where there is a structure of "onion.". It should also be noted that the material is largely transported in both directions (to both sides of the joint). Transport of the material concerns both larger volumes (areas 1 and 3 in the Fig. 5-alloy 2017A and alloy 7075, respectively) as well as small quantities, finally forming a pattern of multiple layers - area 2 in Fig. 5. A similar, significant mixing of materials, visible macroscopically, was reported by Cavaliere et al. (Ref 18) in respect to dissimilar joints of aluminum alloys $6082 / 2024$. The formation of areas consisting of a new chemical composition in the analyzed weld cannot be ruled out as a result of mixing the welded alloys (Fig. 5). Finally, within the weld nugget, three types of microstructure can be observed: separate areas of alloys 2017A and 7075 and the areas which are a result of mixing of both welded materials (with varying degrees and ways of mixing). In addition, on the advancing side (left-hand side of the figure), within the thermo-mechanically affected zone, it can be concluded that there is no concurrent flow material in relation to the FSW tool movement, unlike in the areas located closer to the joint face (see Fig. 3). The possible discussed directions of the material flow in different areas of the weld are the result of the plasticization of the material and its
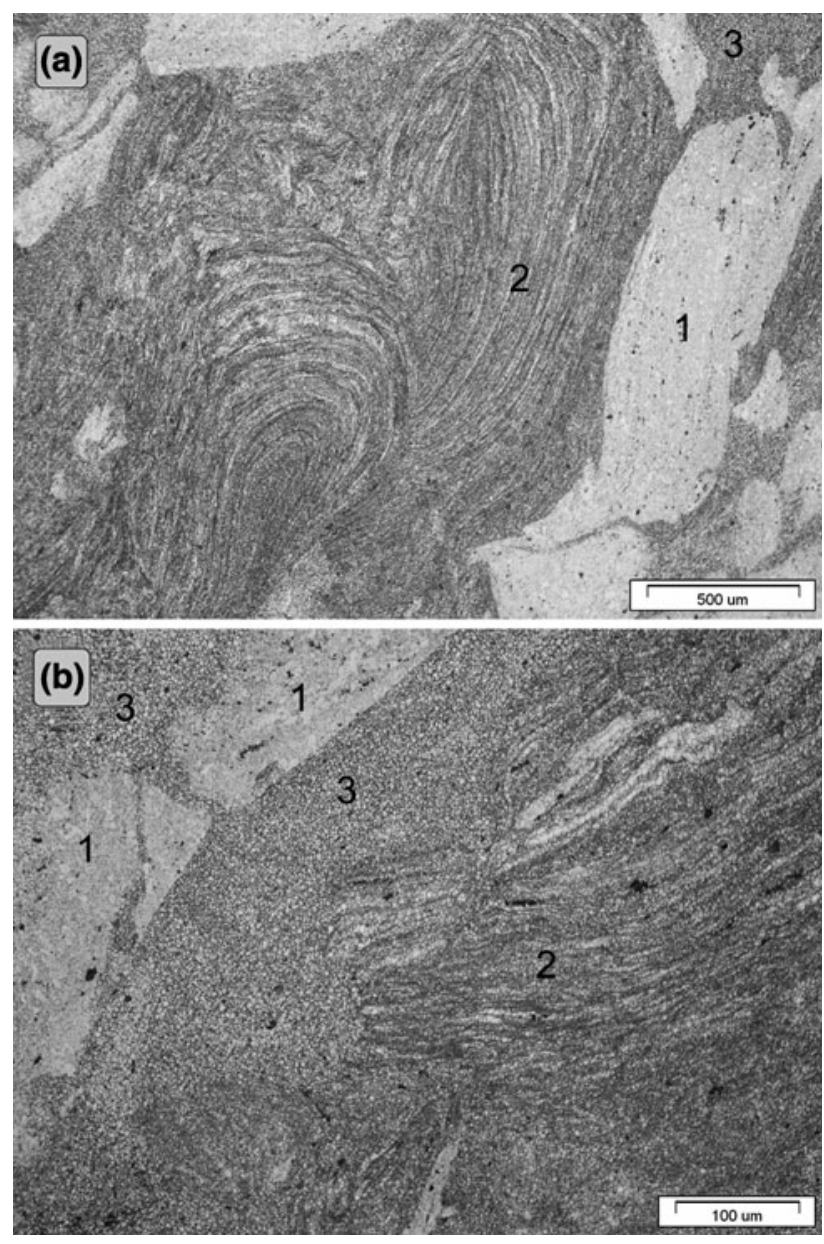

Fig. 5 Microstructure of the stirred zone presented in the Fig. 4 
transport dependent on the FSW tool type. The paper dedicated to FSW welds of aluminum alloys $2024 / 7075$ written by da Silva et al. (Ref 15) demonstrates the flow of the material down from the tool shoulder to the bottom of the weld and transport of material (in this case, the 7075 alloy) in the thread grooves of the FSW tool (conventional tools with a cylindrical pin and a thread on its surface). It largely explains the observed layout of the microstructure. To complement the above considerations, it should be noted that the final condition (structure and appearance) of the microstructure results from numerous factors working in relation to each other. The shape of the particular parts of the tool sets a specific flow of the material. The material flow also depends on its plasticity, and this is associated with (mechanical and physical) features of the welded alloys (e.g., the strengthening state) during welding and thus at a specific temperature. This means that the higher temperature, which increases the plasticity of the material, is at the same time the result of (plastic deformation) and a factor influencing the deformation. Finally, the conditions during the welding process are the superposition of all the factors that give the effect of a specific microstructure. Unfortunately, relations existing between factors cannot be represented as simple functions. For these reasons, despite many works on the FSW technology, a general model of the FSW process has still not been established. Also, for these reasons, a majority of the studies are conducted using the trial-and-error method, and their results are described in the literature. Also, in this way, it was found that the shift of the welding line into the 2017A alloy and the applied position of the alloys (an advancing and retreating side) combined with the set welding parameters give satisfying results.

The last of the analyzed layers (L5) is located just below the weld nugget, so the area is not stirred directly by the welding tool. This is the thermo-mechanically affected zone located near the root of the weld. Nevertheless, the effect of the pin tool moving can be observed. Directions of the flow of the material can be seen across the entire width, which is determined by the diameter of the pin tool (some of them are marked with black arrows)-Fig. 6. Clearly visible is the contact area of welded plates (white arrow indicated). While it is true that the lack of connection within a FSW joint is considered a defect, the analysis of this microstructure allows complementing the characteristics of this type of weld and the manner of flowing of the material during the welding process. The elimination of this defect can be achieved using a tool with a longer pin. However, the applied tool and the welding conditions (described above) can be used without any change to the welding of elements with a thickness of around $5.5 \mathrm{~mm}$.

It has to be noted that the structure of the FSW welds may be evaluated in depth using transmission electron microscopy (TEM). TEM analysis, however, is based on a few grains; performing tests on multiple layers and in different areas of each layer would be prohibitively laborious, although such an evaluation would be interesting and valuable. The focus in the present work was on the direction of flow in specific areas, which could be evaluated using light microscopy.

In addition to microstructure studies, research was done into the surface microstructure of the sample broken in the static tensile test. The tests were performed using a SEM. The place of the rupture of the sample coincides with the contact sheets before welding. The sample was characterized by the lowest strength in this area because the tool did not stir the material across the entire cross section of the weld, as shown in Fig. 1 and in the microstructure of the layer L5-Fig. 6. However, rupture of the sample at this point (Fig. 7) permitted the observation of the fracture surface, which crosses all the layers discussed above. The retreating side of the weld was observed using the SEM (right-hand side in Fig. 7). Figure 8 shows microstructure of the L4 layer (weld nugget). The fracture is mostly ductile, though to a limited extent. However, one can define it as a ductile fracture, similar in structure to those described in Ref 18, which relate to dissimilar FSW welds including aluminum alloy 2024. In the middle part, however (Fig. 8), areas with smooth surfaces are visible (e.g., area 1) with no signs of plastic deformation. This means that the forces of cohesion in these areas were much smaller in relation to the yield strength of the surrounding material. Taking into account the place of observation (the weld nugget) and the analysis of macro- and microstructure of layer L4 (Fig. 4 and 5), one can conclude that the visible surface is the boundary between alloys which exist separately. In that case, a visible area on the fracture (flat surface) probably consists of alloy 7075 surrounded by alloy 2017A or of a mixture of these alloys. This conclusion follows from the SEM-EDS analysis of particles located in the fracture (area 2 in Fig. 8) - particles contain mainly $\mathrm{Al}$ and $\mathrm{Cu}$. This indicates the type $\mathrm{Al}_{2} \mathrm{Cu}$ particles occurring in alloy 2017A.

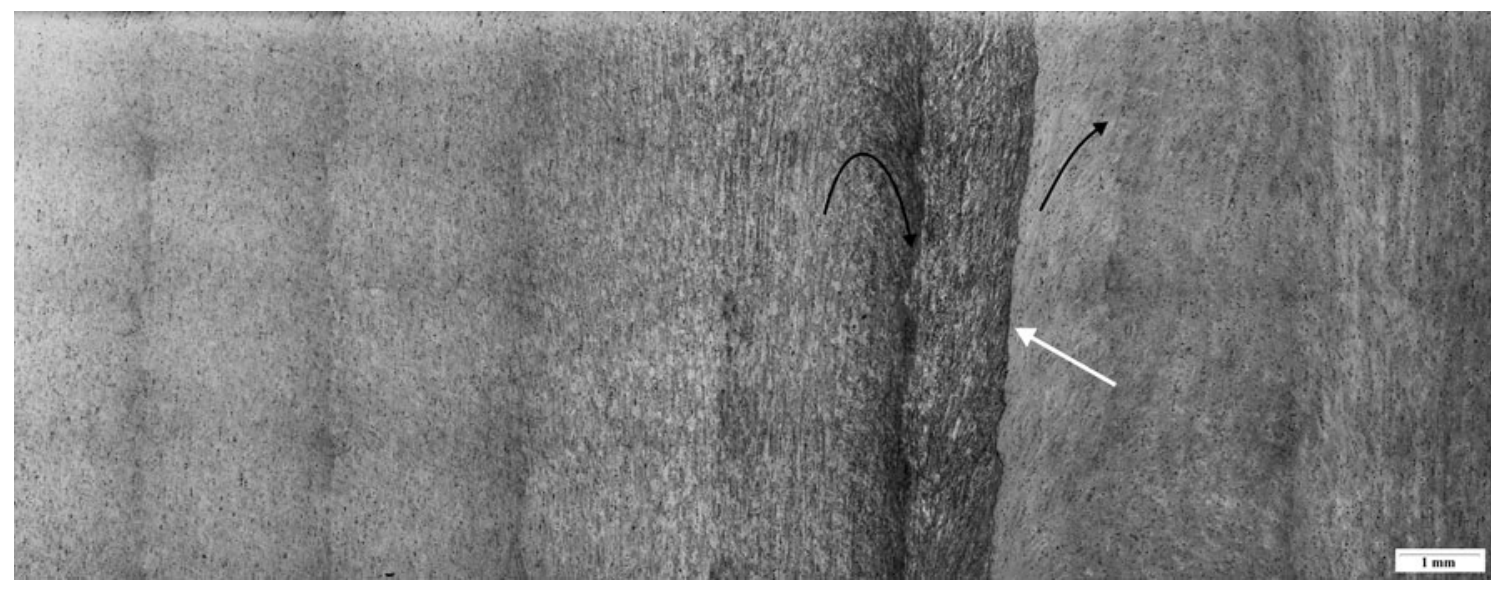

Fig. 6 Macrostructure of L5 layer of the weld- $4.9 \mathrm{~mm}$ from the face of the weld 


\section{Mechanical Properties}

Microhardness distribution on cross sections of FSW welds is an approved and widely used approach to reveal mechanical behavior of individual weld areas. In the study, the distribution of hardness rather than hardness of individual areas was characterized. This allows the determination of hardness in the weakest areas where the samples are usually broken in the static tensile test. Therefore, microhardness measurements were carried out to investigate the mechanical properties of the weld. The layers L1-L5 and two additional layers (situated at a distance of 1.6 and $5.5 \mathrm{~mm}$ from the face of weld) were analyzed. Measurements were performed twice on each layer at a distance of $2.2 \mathrm{~mm}$ (Measurement 1) and $3.7 \mathrm{~mm}$ (Measurement 2) from the edge of the sample (from the top of the edge in Fig. 2, 3, 4, and 6). The measurement tracks go across the structure (in a horizontal position in the mentioned figures). The results of the measurements for layer L1 (the one near the face of the weld), layer L4 (weld nugget), and layer L5 (the layer near the root of weld) in the form of a hardness profile are shown in Fig. 9. Hardness distributions for each of the layers indicate the greater hardness of the advancing side (alloy 7075). However, the reported hardness values for both sides of the weld are smaller than the hardness of the parent materials (7075 alloy-195 HV0.1; 2017A alloy-136 HV0.1), which means that changes in microstructure in relation to the parent material (the following as a result of welding process) do not provide for optimal strengthening of the material. The L1 layer (close to the face of weld) exhibits the highest hardness of both sides (advancing and retreating). The large hardness of this layer can be explained by large plastic deformation resulting from the FSW tool shoulder impact. On the retreating side of the weld, the high hardness is also affected by a significant share of the 7075 alloy on this side-Measurement 1 was made at a distance of about $2.2 \mathrm{~mm}$ from the upper edge of the sample - which was transported there from the advancing side (Fig. 2, areas 3-4, and 3). Measurement 2 (running in another area) confirms the greatest hardness of layer L1 (both sides of the weld). Designated hardness profiles for the lower-lying layers L4 and L5 show a narrow region of increased hardness on the advancing side. Therefore, it can be concluded that it is not only the temperature but also the plastic deformation occurring during welding that has a very strong influence on the microstructure of alloy 7075 . Consequently, in the plastically deformed area, this alloy will tend to strengthen. The confirmation of this conclusion is low hardness of alloy 7075 in the HAZ, so the area is not deformed plastically. The impact of such large plastic deformation that occurs during the FSW welding process may facilitate the dissolution of the precipitates due to the facilitated diffusion of elements from dissolving particles (higher density of crystal defects, the crystal lattice deformation, flow of material). As reported by Rajakumar et al. (Ref 8), in aluminum alloy 7075, the strengthening of the material is mainly based on precipitates $\mathrm{MgZn}_{2}$ and $\mathrm{Al}_{2} \mathrm{CuMg}$. However, in the case of $\mathrm{Al}-\mathrm{Zn}-\mathrm{Mg}$ alloys, a temperature sufficient to dissolve the strengthening particles is relatively lower compared to alloys including copper. As reported by RuiDong Fu et al. (Ref 5), the transformation of the microstructure from a supersaturation state to a state of microstructure with hardening phases is as follows: supersaturated solid-solution $\rightarrow$ GP zone $\rightarrow \eta^{\prime}\left(\mathrm{MgZn}_{2}\right) \rightarrow \eta\left(\mathrm{MgZn}_{2}\right)$. This transformation takes place at temperatures below $300{ }^{\circ} \mathrm{C}$. However, Hamilton et al. (Ref 21) reported that the transformation temperature of the microstructure of the 7042-T6 aluminum

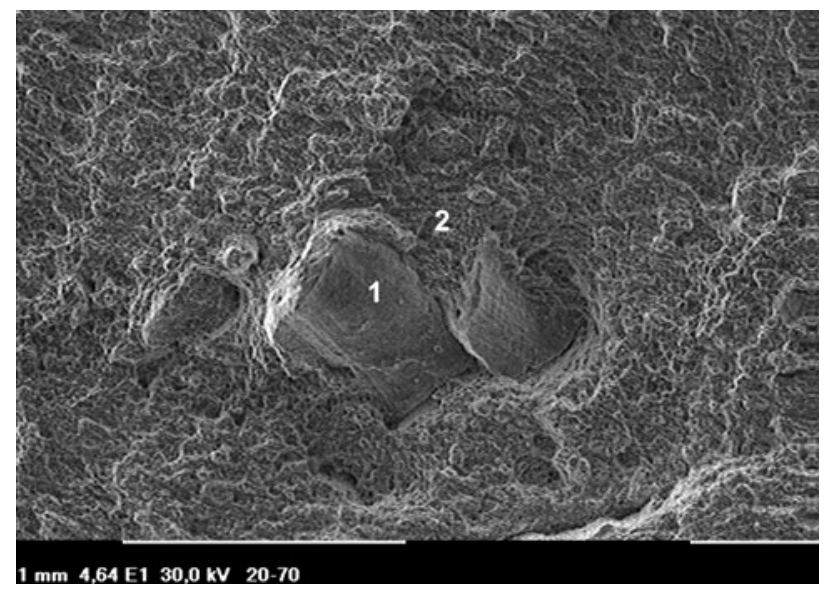

Fig. 8 SEM microstructure of the fracture - on the layer 4 (L4) level

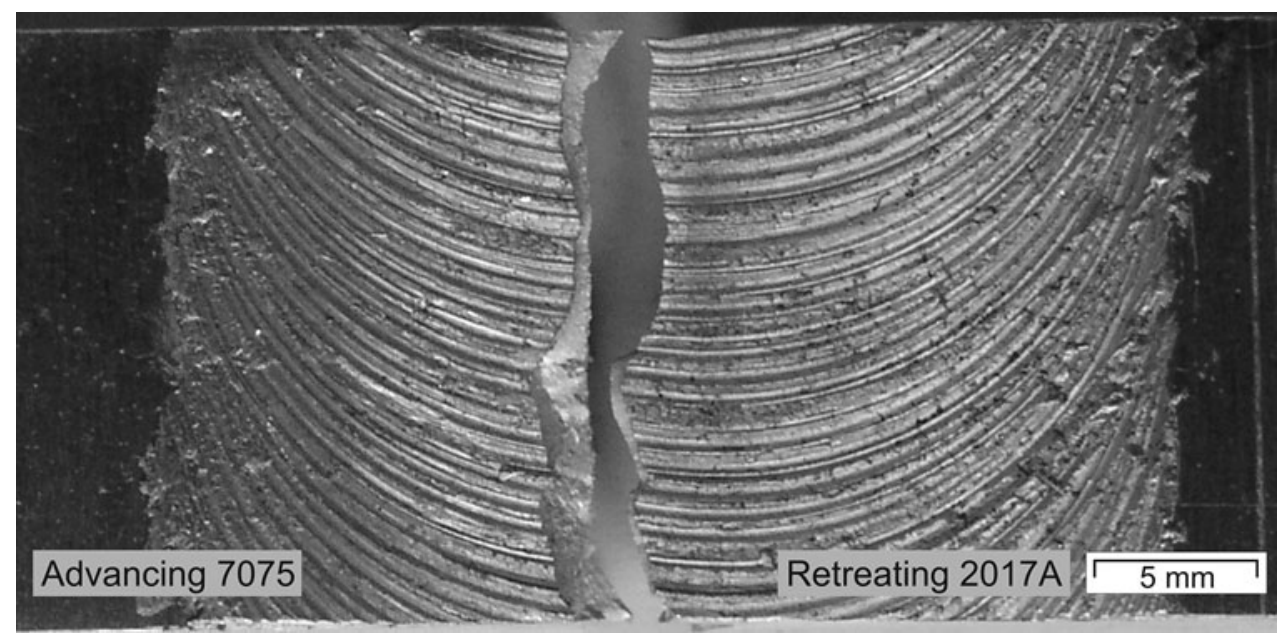

Fig. 7 Photo - the sample ruptured in tensile test 
alloy friction stir welded would likely be higher than $300{ }^{\circ} \mathrm{C}$ because of rapid heating rates. Thus, in areas where supersaturation occurs during welding, the alloy will tend to harden (higher hardness in the middle of the weld). Areas affected by lower temperatures and which are plastically non-deformed (plastic deformation probably fosters supersaturation state) will only show a tendency to weaken (decreasing of hardness) as a result of partial transformation to stable phases. This involves the disappearance of highly fine dispersion-strengthening GP zones, loss of coherence with the matrix, and their possible partial coagulation. In this way, the shape of the curves of hardness (Fig. 9) on the advancing side of the weld (7075 alloy) can be explained, in particular a significant decrease in hardness in the HAZ. A similar distribution of hardness was obtained for the FSW weld of aluminum alloy 7050, as described in the paper ( Ref 5 ) mentioned before.

In turn, in the layer L4, higher hardness is observed on the retreating side of the weld where alloy 7075 is located (see Fig. 4). In alloy 2017A, both in the area of direct mixing by the FSW tool and under the weld nugget (near the root of weld), hardness is reduced (average $125 \mathrm{HV}$ ). This means that the conditions occurring during the welding process do not result in the strengthening of the material and are even the cause for weakening the strengthening mechanisms existing in the parent material. According to Chen et al. (Ref 7) (research on FSW joints 2219 of aluminum alloy), there are conditions that only cause growth of the metastable precipitates in the heat-affected zone during welding. This explains the visible decrease in hardness in the heat-affected zone of alloy 2017A and in the layers below the stirred zone. The area of the weld nugget contains the equilibrium phases (stable) and small supersaturated grains (Ref 7). This proves a significant share of the plastic deformation process in the precipitation transformation in alloys of the 2xxx series, precipitation strengthening, mainly involving $\mathrm{Cu}$ phases. Analysis of the average value calculated on the basis of data (summary-Fig. 10) taken from the hardness profiles of all (seven) studied layers showed the greatest strengthening of the areas near the face of the weld.
The lowest hardness of the layer below the area of stirred material (by the FSW tool) is observed. This hardness distribution will suggest greater resistance to three-point bending when the joint is bent upward grain (tensile forces occur in the upper layers of the face (crown side) of the weld). In addition, what should be noted are small differences in the average values obtained (about 0.5-2 HV for about 60 measurements that were done for each profile) in the two measurement series (Measurement 1 and Measurement 2), except for layer L1 (Fig. 10) where significant differences in the microstructure were identified (Fig. 2).

The SEM microstructure discussed above (Fig. 8) formed as a result of the static tensile test. Despite the existence of a defect in the bottom of the weld, the ultimate tensile strength (UTS) of this weld is good enough $(290 \mathrm{MPa})$, despite the fact that the UTS was calculated with relation to the whole cross section of the weld, excluding the defect at the bottom part of the weld.

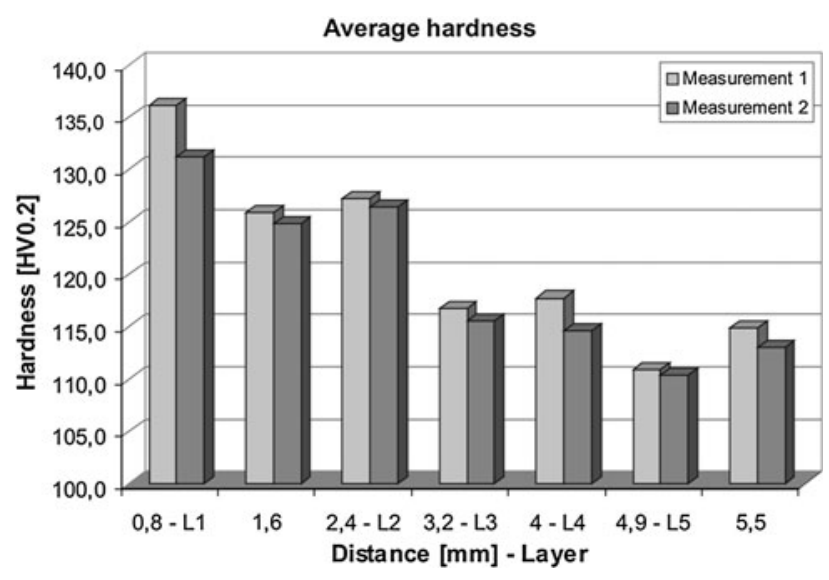

Fig. 10 Average hardness for all layers

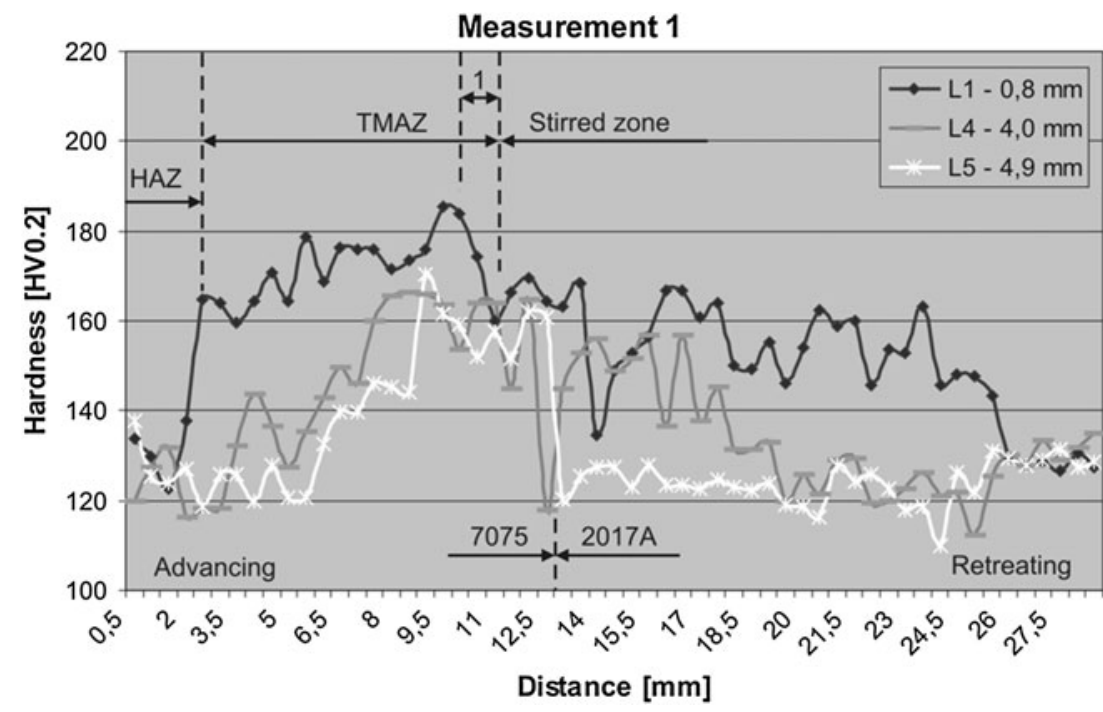

Fig. 9 Hardness distribution of layers L1, L4, L5; 1-area no. 1 in the Fig. 2 


\section{Conclusion}

Based on the analysis of the microstructure and mechanical properties of many cross sections of investigated dissimilar weld, the following points were established:

- In layers near the face of the weld, the FSW tool resulted in mixing the materials, but to a limited extent. The area of the structure composed of the two alloys is mainly located in the material on the advancing side of the weld (alloy 7075). Its width corresponds to the width of the FSW tool which was placed in this material. But, in addition, what was observed was the fact that these areas occurred in the middle of the weld, which also confirms that welding conditions were varied.

- In the middle of the weld, on the advancing side, flow directions of the material are opposite to the direction of rotation of the FSW tool within the thermo-mechanically affected zone and thus to the direction of material flow in the zone where the material is directly stirred.

- Transportation of the material to the weld nugget creates three types of areas: separate volumes containing alloy 2017A, separate volumes containing alloy 7075 , and places containing a mix of the alloys. The boundaries of these areas can be planes, which are less cohesive forces, and this makes it easier cracking ways.

- The welding process caused significant variation in hardness of the material within the weld. The conditions during the welding process caused alloy 7075 to have a tendency to strengthen within the plastically deformed area, while in the heat-affected zone, it has a significant drop in hardness. The area near the face of the weld has a greater hardness than the areas located close to the root of the weld.

\section{Open Access}

This article is distributed under the terms of the Creative Commons Attribution License which permits any use, distribution, and reproduction in any medium, provided the original author(s) and the source are credited.

\section{References}

1. Kh.A.A. Hassan, A.F. Norman, D.A. Price, and P.B. Prangnell, Stability of Nugget Zone Grain Structures in High Strength Al Alloy Friction Stir Welds During Solution Treatment, Acta Mater., 2003, 51, p 1923-1936

2. H. Uzun, C. Dalle Donne, A. Argagnotto, T. Ghidini, and C. Gabaro, Friction Stir Welding of Dissimilar Al 6013-T4 to X5CrNi18-10 Stainless Steel, Mater. Des., 2005, 26, p 41-46
3. O. Hatamleh, A Comprehensive Investigation on the Effects of Laser and Shot Peening on Fatigue Crack Growth in Friction Stir Welded AA 2195 Joints, Int. J. Fatigue, 2009, 31, p 974-988

4. C. Hamilton, S. Dymek, and M. Blicharski, Mechanical Properties of al 6101-T6 Welds by Friction Stir Welding and Metal Inert Gas Welding, Arch. Metall. Mater., 2007, 52(1), p 67-72

5. R. Fu, Z. Sun, R. Sun, Y. Li, H. Liu, and L. Liu, Improvement of Weld Temperature Distribution and Mechanical Properties of 7050 Aluminum Alloy Butt Joints by Submerged Friction Stir Welding, Mater. Des., 2011, 32, p 4825-4831

6. Ch.B. Fuller, M.W. Mahoney, M. Calabrese, and L. Micona, Evolution of Microstructure and Mechanical Properties in Naturally Aged 7050 and 7075 Al Friction Stir Welds, Mater. Sci. Eng. A, 2010, 527, p 2233-2240

7. Y.C. Chen, J.C. Feng, and H.J. Liu, Precipitate Evolution in Friction Stir Welding of 2219-T6 Aluminum Alloys, Mater. Charact., 2009, 60, p 476-481

8. S. Rajakumar, C. Muralidharan, and V. Balasubramanian, Influence of Friction Stir Welding Process and Tool Parameters on Strength Properties of AA7075-T6 Aluminium Alloy Joint, Mater. Des., 2011, 32, p 535-549

9. H.J. Zhang, H.J. Liu, and L. Yu, Microstructure and Mechanical Properties as a Function of Rotation Speed in Underwater Friction Stir Welded Aluminum Alloy Joints, Mater. Des., 2011, 32, p 4402-4407

10. J.-Q. Su, T.W. Nelson, R. Mishra, and M. Mahoney, Microstructural Investigation of Friction Stir Welded 7050-T651 Aluminium, Acta Mater., 2003, 51, p 713-729

11. H. Fujii, L. Cui, M. Maeda, and K. Nogi, Effect of Tool Shape on Mechanical Properties and Microstructure of Friction Stir Welded Aluminum Alloys, Mater. Sci. Eng. A, 2006, 419, p 25-31

12. A. Wójcicka and Z. Wróbel, The Panoramic Visualization of Metallic Materials in Macro- and Microstructure of Surface Analysis Using Microsoft Image Composite Editor (ICE), Lecture Notes in Computer Science, 7339/2012, 2012, p 358-368

13. M. Peel, A. Steuwer, M. Preuss, and P.J. Withers, Microstructure, Mechanical Properties and Residual Stresses as a Function of Welding Speed in Aluminium AA5083 Friction Stir Welds, Acta Mater, 2003, 51, p 4791-4801

14. J. Adamowski, C. Gambaro, E. Lertora, M. Ponte, and M. Szkodo, Analysis of FSW Welds Made of Aluminium Alloy AW6082-T6, Arch. Mater. Sci. Eng., 2007, 28(8), p 453-460

15. A.A.M. da Silva, E. Arruti, G. Janeiro, E. Aldanondo, P. Alvarez, and A. Echeverria, Material Flow and Mechanical Behavior of Dissimilar AA2024-T3 and AA7075-T6 Aluminium Alloys Friction Stir Welds, Mater. Des., 2011, 32, p 2021-2027

16. M. Vural, A. Ogur, G. Cam, and C. Ozarpa, On the Friction Stir Welding of Aluminium Alloys EN AW 2024-0 and EN AW 5754-H22, Int. Sci. J., 2007, 28(1), p 49-54

17. P. Cavalierea, R. Nobilea, F.W. Panellaa, and A. Squillace, Mechanical and Microstructural Behaviour of 2024-7075 Aluminium Alloy Sheets Joined by Friction Stir Welding, Int. J. Mach. Tools Manuf., 2006, 46, p 588-594

18. P. Cavaliere, A. De Santis, F. Panella, and A. Squillace, Effect of Welding Parameters on Mechanical and Microstructural Properties of Dissimilar AA6082-AA2024 Joints Produced by Friction Stir Welding, Mater. Des., 2009, 30, p 609-616

19. K. Mroczka, J. Dutkiewicz, L. Lityńska-Dobrzyńska, and A. Pietras, Microstructure and Properties of FSW Joints of 2017A/6013 Aluminium Alloys Sheets, Arch. Mater. Sci. Eng., 2008, 33(2), p 93-96

20. C. Hamilton, A. Sommers, and S. Dymek, A Thermal Model of Friction Stir Welding Applied to Sc-Modified Al-Zn-Mg-Cu Alloy Extrusions, Int. J. Mach. Tools Manuf., 2009, 49, p 230-238

21. C. Hamilton, S. Dymek, and O. Senkov, Characterisation of Friction Stir Welded 7042-T6 Extrusions Through Differential Scanning Calorimetry, Sci. Technol. Weld. Join., 2012, 17(1), p 42-48 